\title{
UK agricultural funding leans towards policy
}

London. Agricultural scientists are concerned that changes in the way the Ministry of Agriculture, Fisheries and Food (MAFF) commissions research will damage their work.

Starting in 1994, MAFF will spend 5 per cent of its budget on projects of its own choosing, selected through competitive bids, rather than waiting for researchers to submit their ideas and picking the best ones. As one academic commented, it is like saying to the researcher, "if you are going to have a bright idea, this is the one you ought to have". In a current annual budget of $£ 137.3$ million (US\$260 million), the new approach would receive $£ 7$ million. MAFF hopes to increase that amount if all goes well.

MAFF also wants to make the organizations it funds more responsive to its needs by shortening the time required to notify them of changes in the nature or scope of their funding. It now informs recipients a year in advance of the end of a grant and six months in advance if new work is to be commissioned.

MAFF research contracts are the principal source of funding for some Agricultural and Food Research Council (AFRC) institutes and research associations. In many cases, the work they do is not duplicated elsewhere, and there is insufficient expertise to take up research work that is lost.

The council will be getting $£ 1.5$ million less from the ministry beginning next April in the first of a series of annual budget cuts. MAFF currently spends $£ 34$ million with the AFRC. While the AFRC is confident that its researchers will win back a large proportion of the money through competitive bids, institutes fear that the new approach will mean an uncertain future for many scientists.

"Competitive tendering may be an exercise we can only do once", says one AFRC researcher. "Many of these people will not be there in 12 months' time to tender again." The impact of the change will be felt even on those groups not receiving contracts from MAFF. "We try very hard to link work that is funded by different sources", says the AFRC scientist, "but the [new system] will break up the continuity."

MAFF's quest for greater flexibility reflects the growing importance of policy considerations in setting out the research agenda. Over the last few years, budgetary responsibilities for research and development have largely been transferred to policy groups, with scientists as advisers. Priorities have changed accordingly; for instance, the emphasis in food research has switched from the underlying technology to safety and nutrition.

Changes in priority are particularly damaging when they occur on short notice. The explosion of interest in bovine spongiform encephalopathy (BSE), or mad cow disease, deprived other related areas of both funds and personnel. Some researchers fear that BSE teams could be hurt when the emphasis changes again. In the meantime, postings tend to be short-term and the people involved complain of being picked up and dropped according to the fashion, without regard for the quality of their work.

"The final line does not seem to relate to the quality of the science", says one senior AFRC researcher. "It's not a science-driven process any more."

The emerging structure favours agricultural organizations such as the research associations and Horticulture Research International, an independent body formed two years ago from an AFRC institute and the horticultural units of MAFF. They are organized along more commercial lines and operate fewer long-term 'public good' research programmes, allowing them to respond faster to customer demands.

Ian Mundell

\section{Germany links biology centres}

Munich. Germany has taken its first step towards improving its biomedical research by linking five large research centres. These include the large cancer research centre in Heidelberg and the newly saved MaxDelbrück Centre for Molecular Medicine in Berlin-Buch, eastern Germany.

The network of institutes will share committees to oversee appointments and to evaluate the research done in each unit. Evaluation committees will be international, and research activities in the institutes will be loosely coordinated.

\section{MITI prepares to fund cold fusion by another name}

Tokyo. At a time when few scientists believe in cold fusion, Japan's powerful Ministry of International Trade and Industry (MITI) is ready to spend millions of dollars on the phenomenon that grabbed headlines worldwide in 1989.

Last week, the ministry's Natural Resources and Energy Agency confirmed newspaper reports that it is hoping to start a government-industry project in the next fiscal year (beginning 1 April 1993) to pursue possible application of cold-fusion experiments in the energy industry. It would be the first significant government funding of cold-fusion research in Japan. MITI's move follows recent claims by Akito Takahashi of Osaka University of excess heat generated by passing an electric current through palladium electrodes immersed in heavy water - much as chemists Stanley Pons and Martin Fleischmann reported in 1989.

Tomihiro Taniguchi, director of the agency's Electric Power Technology Division, says that MITI is not claiming that Takahashi's experiments involve fusion, preferring to call the phenomenon "hydrogen energy". MITI's reluctance to use the words 'cold fusion' stem from scepticism of the phenomenon and its desire not to appear to be encroaching upon the research territory of other ministries.

Most Japanese scientists abandoned coldfusion research after an initial burst of enthusiasm in 1989. But a small number of die-hard enthusiasts in the universities have continued experiments using the small annual grants of a few million yen (US $\$ 1,000$ $\$ 2,000$ ) that university departments receive from the Ministry of Education, Science and Culture. Taniguchi says the project must still be discussed internally before the ministry submits a budget request at the end of next month. But he expects it to be "hundreds rather than tens of millions of yen" to support a laboratory with researchers from academic institutions and industry.

Electric utility companies and material processing industries are interested, Taniguchi says. MITI would like to persuade the "rather conservative" energy industry to back this "high-risk basic research", he says, because of its potential for a "big payoff".

Japan's leading 'hot' fusion researchers are adopting a wait-and-see attitude. Although they are not yet convinced that the ministry will in fact spend the money on cold fusion, they seem prepared to tolerate the initiative if no claims of fusion are made. As one leader of fusion research puts it, "cold fusion is not science".

David Swinbanks 